\title{
Um monumento \\ "colonial" para uma \\ cidade moderna: \\ o conjunto jesuítico do \\ Pátio do Colégio nas \\ comemorações do \\ IV Centenário de São Paulo
}

Roberto dos Santos Canado*

Resumo 0 artigo aborda as mobilizações em prol da reconstrução do conjunto arquitetônico jesuítico do Pátio do Colégio, em São Paulo. Tais mobilizações resultaram na aprovação da Lei Estadual n 2658 de 1954. Por meio desse instrumento legal, ocorreu a doação da área correspondente ao antigo Colégio aos jesuítas, representados pela Sociedade Brasileira de Educação, e ainda previu a reconstrução como parte das comemorações do IV Centenário de São Paulo. É objetivo desse artigo abordar a dimensão política dessa reconstrução e compreender o seu papel discursivo perante outras iniciativas de comemoração do IV Centenário, com destaque para o Parque Ibirapuera.

Palavras-chave: Pátio do Colégio, história de São Paulo, patrimônio cultural.

Un monumento "colonial" para una ciudad moderna: el conjunto jesuítico del Patio del Colegio en las celebraciones del IV Centenario de São Paulo

Resumen El artículo tiene por objetivo abordar las movilizaciones en favor de la reconstrucción del conjunto arquitectónico jesuítico del Patio del Colegio, en São Paulo. Tales movilizaciones resultaron en la aprobación de la Ley Estadual $n^{\circ} 2658$ de 1954. Por medio de ese instrumento legal, ocurrió la donación del área correspondiente al antiguo Colegio a los jesuitas, representado por la Sociedad Brasileña de Educación, y aun previó la reconstrucción como parte de los programas conmemorativos del IV Centenario de São Paulo. Es objetivo de ese artículo abordar la dimensión política de esa reconstrucción, y entender su papel discursivo ante otras iniciativas de celebración del IV Centenario, con destaque al Parque Ibirapuera.

Palabras clave: Patio del Colegio, historia de São Paulo, patrimonio cultural.
A colonial monument to a modern city: the jesuit complex of Patio do Colégio in the celebrations of the fourth Centenary of São Paulo

Abstract This article aims to address the mobilizations for the reconstruction of the Jesuit architectural complex of Pátio do Colégio, in São Paulo. Such mobilizations resulted in the approval of the State Law $n^{\circ} 2658,1954$. By means of this legal instrument, the area corresponding to the former school was donated to the Jesuits, represented by the Brazilian Society of Education, and its reconstruction was also foreseen as part of the IV Centenary of São Paulo celebration programs. The purpose of this article is to approach the political dimension of this reconstruction and to understand its discursive role towards other IV centenary celebrations initiatives, focusing on Parque Ibirapuera.

Keywords: Pátio do Colégio, history of São Paulo, cultural heritage. 
s comemorações do IV Centenário de São Paulo têm sido qualificadas como momento significativo para apreensão do percurso histórico da cidade nos anos 1950, seja do ponto de vista urbano, com as diversas transformações decorrentes dos referidos programas comemorativos, seja do ponto vista social, uma vez que a própria Comissão encarregada para a organização dos festejos aglutinou em seus quadros atores sociais de origem imigrante ligados a indústria, com destaque para Ciccilo Matarazzo, presidente da Comissão por longo período.

A historiografia foi pródiga ao apontar o IV Centenário como expressão das mudanças da cidade de meados do século, com seus crescimentos urbano e demográfico, seu incremento industrial, seus rearranjos sociais e seu cosmopolitismo, ou seja, todos os atributos de uma cidade moderna.

A autora Maria Arminda Arruda que definiu para a cidade de São Paulo os anos 1950 como um momento em que se vivia uma "suspensão da história, um verdadeiro corte em relação ao passado" qualificou as comemorações do IV Centenário como a expressão do "desejo de projetar uma imagem da São Paulo progressista e moderna" (ARRUDA, 2001, p. 71).

Silvio Luis Lofego, por sua vez, ao discutir o papel das comemorações como uma forma de propagandear São Paulo num cenário nacional e destacar a sua liderança como a "cidade que mais cresce no mundo", apontou o IV Centenário como momento de celebração não apenas dos quatrocentos anos da cidade, mas também de apresentação de São Paulo como uma "das metrópoles mais modernas do planeta" (LOFEGO, 2004, p. 52).

Por fim, Paulo Cesar Garcez Marins abordou o Parque Ibirapuera, inaugurado por ocasião do IV Centenário, como um "novo marco zero" da cidade que naquele momento almejava (re)fundar-se sob o signo do moderno, veiculado nos edifícios projetados por Oscar Niemeyer (MARINS, 2003, p. 33).

No entanto, apesar do predomínio do presente ou da opção pelo depois, não faltaram nos programas comemorativos menções ao passado, conforme demonstram os autores supracitados. Arruda, por exemplo, destacou a produção de estudos históricos da cidade publicadas pela Biblioteca do IV Centenário1. Já Garcez chamou a atenção para as alegorias bandeirantes monumentalizadas no Parque Ibirapuera (MARINS, 2003).

* Roberto dos Santos Canado Junior é Historiador, Doutorando em Arquitetura e Urbanismo pela Faculdade de Arquitetura e Urbanismo da Universidade de São Paulo, ORCID <https://orcid. org/0000-0002-3805-8481>.
Essas diferentes tendências, certamente, eram corolário das mudanças sociais da cidade, das tensões entre novos e velhos atores que disputavam por meio de símbolos erguidos na paisagem urbana um papel de liderança política, econômica e cultural, ao mesmo tempo em que buscavam atrelar-se à história da cidade. Enquanto os novos atores sociais advindos da imigração, desenraizados, valoravam as novas construções, as velhas elites ligadas à terra aferram-se na defesa dos tradicionais valores paulistanos. 

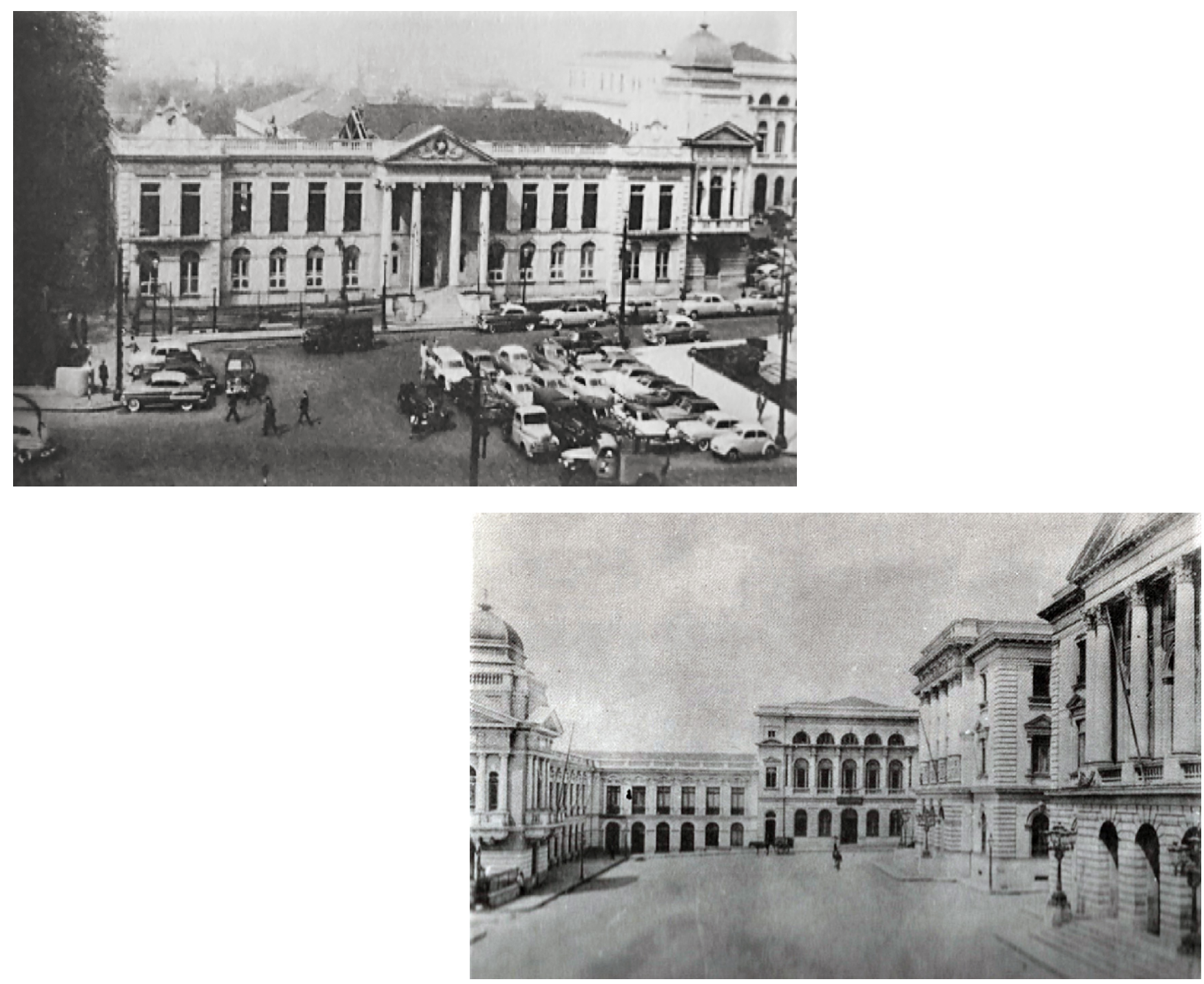

Figura 1 (topo): Edifício público situado no local do antigo Colégio jesuíta, então ocupado pela Secretaria Estadual da Educação, 1953. Fonte: MORAES (1979, p. 129).

Figura 2: Área antes ocupada pela antiga Igreja jesuíta transformada em leito carroçável, 1908. Fonte: LIMA (2003, p.69).

1 ARRUDA, Maria Arminda do Nascimento. Metrópole e Cultura: São Paulo no meio do século XX. Bauru, SP: Edusc, 2001. A autora citou algumas obras de caráter histórico publicadas pela Biblioteca do IV Centenário: “Dicionário de Bandeirantes e Sertanistas do Brasil, de Francisco de Assis Carvalho Franco; Bibliografia Crítica da Etnologia Brasileira de Herbert Baldus; São Paulo Antigo. Plantas Diversas. p. 95
Grande parte dos esforços das velhas elites concentrou-se nas obras de reconstrução dos antigos edifícios do Pátio do Colégio. Essas obras que seriam concluídas apenas no final da década de 1970 foram iniciadas em 1954 por ocasião do IV Centenário da cidade de São Paulo. O longo período resultou da demora para aquisição da área completa pertencente ao antigo conjunto jesuítico. Em 1954, os requerentes das obras adquiriram junto ao poder público estadual apenas o terreno correspondente ao antigo Colégio [figura 1], já o trecho da Igreja, naquele momento leito carroçável [figura 2], deveria ser pleiteado na esfera administrativa municipal (CANADO JUNIOR, 2014).

Apesar das inúmeras mobilizações, das suas controvérsias ou até mesmo do impacto urbano e visual que acarretou para o denominado centro velho da cidade, a reconstrução do conjunto jesuítico foi pouco abordada pelos mencionados estudos do IV Centenário. De modo que é objetivo desse artigo destacar a importância da reconstrução para os segmentos sociais que a viabilizaram, assim como inferir os sentidos de recuperar os valores embutidos nos edifícios coloniais e religiosos no contexto das comemorações. Para tanto, busca-se esquadrinhar os atores líderes da reconstrução, indicando suas inserções sociais e suas manifestações públicas na imprensa da época favoráveis à reconstrução do Pátio do Colégio. 
2 A RECONSTRUÇÃO dos primitivos edifícios. O Correio Paulistano, São Paulo, pp. 1-2, 17 dez. 1953

\section{Cavaleiros, católicos e quatrocentões}

No dia 17 de dezembro de 1953, o jornal O Correio Paulistano publicou uma matéria em que relatava as articulações e as tentativas de reconstrução dos antigos edifícios jesuíticos do Pátio Colégio. Segundo José Nunes Vilhena, um dos defensores da reconstrução entrevistado pelo Correio, até aquele momento duas campanhas haviam fracassado e uma terceira estava em curso para levar a cabo tal empreitada.

A primeira mobilização favorável à retomada da antiga feição do Pátio do Colégio, ocorreu ainda no final dos anos 1940 e resultou no chamado "Livro de Ouro" contendo 4 mil assinaturas de "pessoas gradas e influentes", conforme opúsculo que circulou em 1954 já divulgando o projeto de reconstrução (CASTSO, 1954). A segunda tentativa ocorreu em 1950 com a formação de uma Comissão pela A.S.I.A (Aniqui Societatis lesu Alumni), antigos alunos de jesuítas, a qual "extinguiu-se sem nada conseguir"2. A terceira e bem-sucedida mobilização também acarretou em uma Comissão, a Comissão Pró Monumento Histórico da Fundação de São Paulo.

Formada em 1953, a Comissão Pró Monumento agregou novamente "figuras exponencias da venerável Companhia de Jesus e ilustres membros da A.S.I.A" (SÃO PAULO, 1953, pp. 39-40). No entanto, as iniciativas em prol da reconstrução não ficaram circunscritas à ordem religiosa dos jesuítas, tampouco aos seus antigos alunos, sendo encampada em sua longa trajetória, por figuras de diferentes segmentos sociais, embora tenha predominado a atuação de atores identificados com setores católicos e conservadores da sociedade paulistana, para os quais reconstruir os antigos edifícios significava "reviver o nascimento de São Paulo" e "cumprir uma elevada missão histórica, cívica, cultural e religiosa" (SÃO PAULO, 1953, p. 59).

Desse modo, ao reivindicarem a reconstrução do Pátio do Colégio atrelavam aos antigos edifícios coloniais jesuíticos argumentos de acentuado cunho classista tendo em vista refazer as suas filiações - senão consanguínea ao menos espiritual - com os antigos fundadores da cidade e pontuar a importância, presente e pretérita, que tinham para a cidade. Tal propósito não impediu, porém, que alguns imigrantes e seus descendentes acabassem por se associar a reconstrução, evidenciando nesse caso o caráter catalisador da religião, que pretendia transcender e agrupar "antigos" e "novos" paulistanos.

Afora os religiosos que compunha a referida Comissão, os seus integrantes leigos se expressavam e eram tidos publicamente como ativos defensores da fé católica, sobretudo da figura do jesuíta José de Anchieta. O perfil desses atores sociais ou o seu envolvimento em eventos e campanhas de caráter religioso foram extensamente publicados em artigos, breves perfis biográficos, em colunas sociais e obituários dos jornais da época.

O político Altino Arantes, por exemplo, que integrou a Comissão Pró Monumento Histórico do Pátio do Colégio, foi "festejado" pelo Correio Paulistano por ocasião de seus 80 anos, em 1956, por estar "a frente de todos os movimentos religiosos de São Paulo" e por ser, "sem dúvida, um grande paladino do catolicismo no Brasil" (LEITE, 1956, p. 6). 
3 AOS ELEITORES associados à confederação das famílias cristãs. O Estado de São Paulo, São Paulo, p. 4, 3 out. 1954.

4 CAMPANHA pela canonização do padre José de Anchieta. $O$ Correio Paulistano, São Paulo, p. 513 jul.1962.

5 MONUMENTO á Anchieta. FoIha da Manhã, São Paulo, p. 3, 29 jun. 1954; INAUGUROU-SE ontem na praça da Sé o monumento ao padre José de Anchieta. Folha da Manhã, São Paulo, p. 7, 9 dez. 1954

6SERÁ entregue um pergaminho ao papa em nome da união dos amigos da padroeira de Brasil. Folha da Manhã, São Paulo, 20 mai. 1956; CAMPANHA da saca de café para a basílica de N. S. Aparecida. Folha da Manhã, São Paulo, p. 5, 1 mai. 1958; PRÓ-CONSTRUÇÃO da basílica da padroeira do Brasil. Folha da Manhã, São Paulo, p. 3, 13 jul. 1958.

7 SALGADO, José Augusto Cesar. o Pátio do Colégio: História de uma Igreja e uma Escola. São Paulo, Gráfica Municipal de São Paulo, 1976.
José Nunes Vilhena, primeiro secretário da Comissão, publicou em 1956 no mesmo Correio o artigo "Centenário da chegada de Anchieta no Brasil", em que exaltou o jesuíta como o "plasmador do espirito da nossa nacionalidade, consolidador da nossa civilização e criador da cidade de São Paulo, eleito seu primeiro cidadão" (VILHENA, 1956, p. 6).

Jose Alves Palma ao mesmo tempo em que se envolvia com as mobilizações favoráveis à reconstrução candidatava-se ao cargo de deputado federal pelo Partido Social Democrático (PSD) e, conforme informativo veiculado no Estado de São Paulo, com grande apoio das Confederação das Famílias Cristãs, uma vez que defendia "os sagrados direitos da família legitimamente constituída" e a "continuidade de "nossas tradições cristãs" 3 .

Por fim, Cesar Salgado, um dos atores mais atuantes nos debates públicos em torno da reconstrução, foi veiculado pela imprensa como mentor intelectual e presidente da campanha pela canonização de José Anchieta iniciada na década de $1960^{4}$, bem como um ativo membro da campanha para a ereção do monumento à Anchieta na

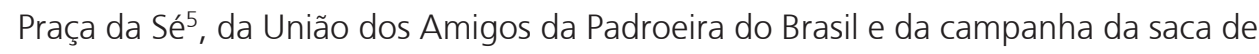
café pró Basílica de N. S. Aparecida ${ }^{6}$.

Outro traço qualificativo e comum entre os atores empenhados pela reconstrução foi a sua origem social e genealógica, filiada aos membros das elites agrárias cafeicultoras de origem colonial, cujas denominações, carregadas de sentidos identitários, variavam de "quatrocentões", "paulistas de quatrocentos anos" ou, simplesmente, descendentes dos "barões do café".

Ao estudar essas elites e os mecanismos por elas criados para distingui-las socialmente, Maria Helena Trigo salienta que além da devoção católica era também marcante nesse segmento social a escolha pelas letras jurídicas, sobretudo pela Faculdade de Direito do Largo São Francisco (TRIGO, 2001). De acordo com as informações biográficas coletadas nos periódicos, entre os membros da Comissão, diplomaram-se no Largo São Francisco, Cesar Salgado, Lúcio Cintra do Prado, Altino Arantes e José Alves Palma, os três primeiros tiveram ainda formação escolar católica no Colégio jesuíta São Luís.

Dentre os nomes que defenderam a reconstrução, o de José Augusto Cesar Salgado teve destaque, pela recorrência com que apareceu nos jornais paulistanos da época. Além de suas constantes aparições na imprensa defendendo as obras, Cesar Salgado presidiu a Comissão Pró Monumento Histórico do Pátio do Colégio até a sua morte em abril de 1979 (dois meses antes da inauguração dos edifícios), e ainda publicou o livro O Pátio do Colégio. História de uma Igreja e de uma Escola ${ }^{7}$, editado pela prefeitura de São Paulo em 1976.

Um breve perfil de Cesar Salgado pode sintetizar os atributos imputados aos postulantes da reconstrução, na medida em que se configurou quase como arquétipo das elites conservadoras, católicas e "quatrocentonas".

Nascido em 1897 na cidade de Pindamonhangaba, localizada no Vale da Paraíba, Cesar Salgado teve suas trajetórias escolar e profissional iniciadas nas cidades vizinhas. As primeiras letras foram aprendidas no colégio jesuíta São Luís de Itu e no São Joaquim 
8 TRIGO, Maria Helena Bueno. Os Paulistas de Quatrocentos Anos: Ser e Parecer. São Paulo, Annablume, 2001. p. 33. Ao abordar o PRP, a autora afirmou que "o Partido Republicano Paulista (PRP) foi dominado por esse grupo ["quatrocentões"], que exercia rigoroso controle sobre as filiações ao partido. Os critérios adotados nas atitudes e nos julgamentos pelos partidários do PRP eram marcadas pelo conservadorismo e pelo patriarcalismo".

9 HOJE a posse do Sr. Cesar Salgado no cargo de Procurador-Geral da Justiça. Folha da Manhã, São Paulo, 3 fev. 1951; JOSÉ Augusto Cesar Salgado. O Estado de São Paulo, São Paulo, p. 21, 10 abril 1979.

10 D. MARIA Antonieta Cesar Salgado. O Estado de São Paulo, São Paulo, p. 5, 16 ago. 1957.

11 CENTENÁRIO de Maria Antonieta Cesar Salgado. Folha de São Paulo, São Paulo, p. 2, 9 mai. 1963.

12 A ASSOCIAÇÃO dos cavaleiros de São Paulo e as comemorações do próximo dia 25. Folha da Manhã, São Paulo, p. 10, 22 jan. 1957.

13 MISSA campal em São Vicente para comemorar a chegada àquela enseada dos primeiros jesuítas. Folha da noite, São Paulo, p. 1, 26 jan. 1954.

14 EXCURSÃO a cidades tradicionais do estado. Folha da manhã, São Paulo, p. 6, 12 mar. 1955. em Lorena; já o seu diploma superior foi adquirido em 1917 na Faculdade de Direito do Largo São Francisco. A sua carreira pública, embora tenha chegado ao auge na cidade de São Paulo - onde foi eleito deputado pelo Partido Republicano Paulista ${ }^{8}$ (PRP) em 1934 e nomeado procurador geral de Justiça do Estado pelo governador Lucas Nogueira Garcez em 1951 - foi iniciada como promotor público nas cidades de Atibaia e Socorro?.

A filiação elitizada de Cesar Salgado, atrelada à terra e à cafeicultura, adveio muito de seu tronco familiar materno. Sua mãe, Maria Antonieta Cesar Salgado, pertencia, conforme afirmado pelo jornal O Estado de São Paulo na ocasião de seu falecimento em 1957, "a uma tradicional família de Pindamonhangaba"10. Em 1963, por ocasião do centenário de nascimento de Maria Antonieta Cesar, o colunista social do jornal Folha da Manhã, Tavares de Miranda, destacou as linhagens da "dama paulista", afirmando ser ela uma descendente "pelo lado paterno, de velhos troncos paulistas da gentílica cidade do Vale do Paraíba [Pindamonhangaba] e pela linhagem materna era neta dos viscondes de Guaratinguetá ${ }^{11}$.

José Augusto Cesar Salgado foi profícuo na participação de entidades e campanhas em prol da manutenção ou valoração da história de São Paulo, numa acepção conservadora que a atrelava às velhas elites de origem colonial e imperial. Foi membro - contemporânea e concomitantemente às suas iniciativas favoráveis à reconstrução dos edifícios jesuíticos - do Clube Piratininga e da Associação dos Cavaleiros de São Paulo, entidades ou organizações de forte apelo tradicionalista e católico.

Fundado em 1934, o clube apregoava combater as políticas centralizadoras e intervencionistas do governo Vargas, ao que correspondia valorar as realizações econômicas de São Paulo e o culto à grandiosidade de seu passado regional (MAYUMI, 2008, p. 86). Cesar Salgado foi redator da Revista Paulistânia, publicação do Clube. No editorial n. 5 da revista, de dezembro de 1939, constou que seriam admitidos no clube "os que estimassem a terra, os que venerassem os vultos do seu passado [...] os que cultuassem a sua história, entrecortada de arrojadas arremetidas, de arroubos de enthusiasmo, de coragem e patriotismo e civismo" (MAYUMI, 2008, p. 87).

A Associação dos Cavaleiros de São Paulo foi criada em 1956 sob os auspícios da Companhia de Jesus. Os membros que recebiam o título de Cavaleiro de São Paulo deveriam prestar "juramento de defender as tradições nacionais e paulistas de cunho cultural, moral e cristão". A confraria estabeleceu ainda como seu "objetivo mais imediato a reconstrução da Igreja do Colégio"12. Nos anos 1960, Cesar Salgado presidiu a Associação dos Cavaleiros.

Além de pertencer as referidas instituições, Cesar Salgado participou de inúmeras atividades de caráter religioso e tradicionalista. Em janeiro de 1954, organizou - por meio da Antiqui lesu Alumni Societatis (entidade dos ex-alunos de jesuítas, da qual era presidente) - uma "festa cívica cristã" na cidade litorânea de São Vicente, em homenagem ao desembarque da Companhia de Jesus ${ }^{13}$; em 1955 foi sócio da Cruzada Paulista, campanha de excursão pelas "cidades tradicionais" paulistas promovida pelo Clube Piratininga ${ }^{14}$.

Para a consolidação das vontades de reerguer na paisagem urbana os edifícios jesuíticos do Pátio do Colégio, no entanto, era necessário que todas as mobilizações advindas 
da sociedade civil como a formação de campanhas e comissões e as publicações de livros e artigos em revistas e jornais encontrassem respaldo no âmbito do poder público, uma vez que a área reivindicada pertencia naquele momento ao Estado, do qual dependia qualquer destinação e utilidade dada ao local histórico.

Desse modo, a reconstrução teve uma trajetória inicial no âmbito do poder público estadual paulista, a Assembleia Legislativa do Estado, onde encontrou alguns fundamentais defensores. $O$ apoio público à reconstrução ocorreu por meio da aprovação da Lei n 2658/54, marco inicial do longo caminho que as obras percorreram.

Sancionada pelo governador em 21 de janeiro de 1954, a lei determinou a doação do terreno juntamente com o que ainda restava da antiga construção à Sociedade Brasileira de Educação, entidade de "Obras Sociais Catequéticas e Educacionais da Companhia São Paulo". De acordo com a lei, cabia a entidade religiosa jesuíta "construir um novo Colégio São Paulo e Igreja anexa, tanto quanto possível nos limites das fundações iniciais, e reproduzir em um perfeito renascimento o ato inicial da fundação da cidade" (SÃO PAULO, 1954, p. 1).

A aprovação da lei se valeu da proximidade com o IV Centenário de São Paulo ao mesmo tempo em que incluiu a reconstrução - juntamente com os atributos de culto ao passado católico da cidade - no calendário comemorativo. No breve percurso burocrático da lei de doação do terreno aos jesuítas, duas figuras se sobrepujaram, o deputado Yukishigue Tamura e o governador Lucas Nogueira Garcez.

Yukishigue Tamura foi autor do projeto de lei n. 1477/53 que originou a supracitada lei estadual, nome de origem acentuadamente distinta em comparação com aqueles acima indicados. Essa estranheza foi sentida e relatada pelo próprio deputado, que contou ter sofrido certa resistência daqueles "católicos tradicionais", os quais "não viam com bons olhos um filho de imigrantes, japonês, ser autor de um projeto ligado às tradições católicas e paulistas" (SAKURAI, 2005, pp. 87-97). Apesar da distância entre o imigrante Tamura e as longínquas tradições locais, algumas intersecções entre a sua trajetória e os requerentes da reconstrução podem ser traçadas, sobretudo por meio da religião.

Diferentemente da maioria das famílias imigrantes japonesas que rumavam para cidades interioranas e os trabalhos agrícolas, os pais de Tamura com uma condição razoavelmente abastada logo se instalaram na capital, permitindo que seu filho, longe das lides do campo, se tornasse o terceiro nipo-brasileiro diplomado pela Faculdade de Direito do Largo São Francisco, formadora de boa parte do quadro político paulistano.

Já a sua primeira formação foi marcadamente católica. Além de ter estudado no colégio jesuíta São Francisco Xavier, Yukishigue Tamura foi próximo, durante sua infância, do padre jesuíta Guido del Toro que atuou junto às famílias japonesas no bairro da Liberdade. A religião influenciou também o início da carreira política de Tamura, pois o padre del Toro auxiliou o seu ingresso no Partido Democrata Cristão (PDC).

O argumento de Tamura favorável à reconstrução seguiu a mesma matriz de exaltação ao tradicional e de culto católico. Assim justificou a apresentação de seu projeto de lei: 
15 Folha de São Paulo, São Paulo, p. 30. 10 fev. 1976

16 CAMPANHA de gratidão aos fundadores de São Paulo. Folha da Manhã, São Paulo, p. 1, 24 set. 1955.
17 SÃO PAULO (Estado). Sessão da Assembleia Legislativa. Diário Oficial do Estado de São Paulo, São Paulo, num. 282, ano 63, pp. 38-39, 1953; SÃO PAULO (Estado). Sessão da Assembleia. Diário Oficial do Estado de São Paulo, São Paulo, num. 272, ano 63, p. 39, 1953.

18 CONSIDERA-SE oportuna e necessária a reconstrução da Igreja edificada por Anchieta no Pátio do Colégio. Folha da manhã, São Paulo, p. 7, 6 out.1953. a História de São Paulo e do Brasil confundem-se com a da Igreja Católica, mas, forçoso é admitir-se que um dos principais responsáveis foi a gloriosa Companhia de Jesus [...] fundaram a cidade de São Paulo, nascida de uma escola, de um templo e de um hospital reunidos na histórica Igreja do Pátio Colégio onde realmente se forjou o espirito cristão do povo paulista e brasileiro. (SÃO PAULO, 1953)

A lei fo sancionada pelo governador Lucas Nogueira Garcez que além de não impor restrições ao projeto demonstrou algumas afinidades de classe com os proponentes de reconstrução. Nogueira Garcez foi membro da multissecular Ordem Terceira do Carmo e "cavaleiro fundador" 15 e da Associação dos Cavaleiros de São Paulo. Findado o seu mandato de governador, atuou junto a Campanha de Gratidão aos Fundadores de São Paulo que visava arrecadar fundos para a reconstrução do Pátio do Colégio ${ }^{16}$.

De acordo com Maria Helena Trigo, o apreço que famílias tradicionais ligadas aos cafeicultores e seus descendentes sustentavam pelo passado era estratégico e decorria das constantes crises que começavam a abalar a ordem social da Primeira República e, por conseguinte, a primazia econômica e política das antigas famílias paulistas a partir da década de 1920. Além das flutuações dos preços internacionais do café, outros três fatores associados ao processo de modernização da capital também impulsionaram essas crises: o surto de urbanização por que passava a cidade desde fins do século XIX, o crescimento demográfico motivado pela imigração e o incremento da indústria local (TRIGO, 2001, p. 35).

De fato, a primeira onda de narrativas históricas de São Paulo, estudos genealógicos e construção de monumentos alusivos ao passado paulista correspondeu às transformações do período histórico denominado de "Segunda Fundação de São Paulo", iniciado por volta de 1870, e perdurou durante a Primeira República (SALIBA, 2004). Perante as transformações sociais e urbanas transcorridas nos anos 1950 e a prevalência do moderno nas comemorações do IV Centenário a reconstrução do Pátio do Colégio foi o contraponto, indicativo da presença de um passado que pretendia-se superar, mas que resistia.

\section{Uma cidade quadricentenária entre a tradição e a modernidade}

A vontade de promover a conciliação entre o passado colonial e católico da cidade de São Paulo e o seu presente progresso, desapegado e transformador, deram o tom das falas dos atores proponentes da reconstrução. Explicitamente, as palavras conciliação e reconciliação foram largamente empregadas.

Para os deputados que aprovaram a lei de doação do terreno aos jesuítas, por exemplo, as obras representavam "a conciliação do presente com o passado" e eram ainda "um monumento vivo para o futuro"17. Em texto intitulado Considera-se oportuna e necessária a reconstrução da Igreja edificada por Anchieta no Pátio do Colégio publicado no jornal Folha da Manhã argumentou-se que "a cidade não vive apenas do seu progresso tentacular, com base no concreto armado" 18 .

Para além de referenciar as construções de novos edifícios de linguagem modernista que estavam sendo erguidos na cidade - como o Copan (1951-1952) ou o conjunto arquitetônico do Parque Ibirapuera (1954) - a menção ao "concreto armado" ou ao 
"progresso tentacular" sinalizava para as transformações sociais da cidade, decorrentes em boa medida da ascensão de imigrantes industrias e do cosmopolitismo e dinamismo cultural e econômico por eles implementados e festejados em 1954 como as grandes qualidades da cidade.

Sobrenomes como Matarazzo e Chateaubriand, que não tinham qualquer tipo de relação com as tradições da terra de que tanto falavam aqueles que se empenhavam pela reconstrução do Pátio do Colégio, despontavam por conta seu poderio econômico para posições de lideranças culturais na cidade. As instituições criadas sob os auspícios desses novos atores sociais, como o MAM e o MASP, passavam a rivalizar com as tradicionalistas, e outrora soberanas, IHGSP, Instituto Genealógico ou a Academia Paulista de Letras. Tal processo não ocorreu, porém, sem tensões. Se os novos e cosmopolitas atores despontavam economicamente, os antigos resistiam, principalmente no meio político ainda pouco acessado pelos primeiros.

Essa ambivalência entre o novo e velho e as disputas entre forças sociais antagônicas, renovadoras e conservadoras, permearam os programas comemorativos do IV Centenário, os quais foram iniciados com a abertura da I Bienal Internacional das Artes sob o comando do industrial Ciccillo Matarazzo e terminaram com a restauração da Casa do Bandeirante e o seu rearranjo em museu, com objetos da São Paulo setecentista, nessa ocasião os festejos eram liderados pelo poeta "apaixonado pelas coisas do passado" Guilherme de Almeida.

No entanto, entre o internacional e o regional, para a Comissão do IV Centenário predominou o primeiro. Foi a imagem da cidade internacionalizada e culturalmente ativa que preponderou nas comemorações, enquanto a vertente de cunho regionalista de exaltação de traços da história colonial paulista exprimia-se, mas começava a perder força (MARINS, 2003, p. 13).

Fato significativo dessa voga renovadora foi o descaso da Comissão do IV Centenário, ou mesmo o conflito, com o Instituto Genealógico e a Academia Paulista de Letras, dois bastiões do culto ao passado paulista. Em relação à primeira instituição, a Comissão vetou verbas para a publicação de seus estudos genealógicos de velhas famílias, que primavam por conectá-las, por laços de sangue, aos antigos bandeirantes.

Quanto à Academia de Letras, os embates tornaram-se públicos e foram veiculados nos jornais. Diziam respeito às insatisfações de seus membros com as interferências que a Comissão de Ciccillo promovia em um evento que pretendiam oferecer em comemoração ao IV Centenário. Um curso de História Paulista que só seria financiado pela Comissão com a prerrogativa de que ela o "fiscalizasse". Para Aristeo Seixas, então presidente da Academia, Ciccillo não estava apto para fiscalizar um "curso promovido e dado por acadêmicos", pois era "minguado nas raízes de quatrocentos anos" e "mal se expressa em língua portuguesa" (LOFEGO, 2004, pp. 171-172).

Se a contenção de verbas da Comissão do IV Centenário para eventos por ela já considerados antiquados assinalou para aquilo que, em sua opinião, não deveria ser exaltado, por outro lado, os vultosos $80 \%$ de suas despesas que foram empregados na construção do Ibirapuera salientam a sua vontade de pontuar o espaço urbano com referências para os novos tempos. A área do Ibirapuera, cujos projetos para sua 
transformação remontam aos anos 1920, foi qualificada na ocasião das comemorações como uma oportunidade de explicitar a modernização e o progresso da capital (OLIVEIRA, 2003)

O parque de dimensões jamais vistas abrigou as primeiras construções públicas modernistas de grande impacto na capital paulista, projetadas por Oscar Niemeyer. Nessas construções, o compromisso com o passado ficou ausente. Foram erguidas como símbolos exclusivos da nova fase histórica de cidade, cujas benesses, explicitadas materialmente, passavam a ser incontestes, tanto num plano internacional, dado o reconhecimento que alcançou o arquiteto carioca, quanto nacionalmente, uma vez que a decantada arquitetura moderna em prédios públicos deixava de ser primazia do Rio de Janeiro com o seu icônico edifício do MEC ou de Belo Horizonte, com o também já celebrado conjunto da Pampulha.

Ressalta-se ainda que ao lado dos pavilhões modernos de Niemeyer, figuraram monumentos que aludiam a eventos caros para ao passado paulista: o Obelisco e Mausoléu ao Soldado Constitucionalista de 32 e o Monumento às Bandeiras. Ambos os monumentos, por sua vez, representaram os estertores da celebração pública e urbana das alegorias bandeirantes e do passado colonial paulista. As próprias formas de abordar e veicular esse momento histórico estavam em transformação.

Tanto para Victor Brecheret, autor do Monumento às Bandeiras, quanto para Ciccillo, exibir nominalmente os bandeirantes ou personalizá-los soava excludente, pois representava apenas alguns indivíduos a eles ligados genealogicamente. De modo que o monumento encampado como parte do IV Centenário deveria ser mais agregador, dar conta, enfim, daqueles múltiplos atores que então compunham a sociedade paulistana, sobretudo aqueles industriais imigrantes responsáveis por sua pujança econômica: "o que importava a Brecheret e aos demais proponentes era destacar a força, o avanço da massa humana aos sertões, às terras desconhecidas - algo compartilhável pelos imigrantes recém-chegados" (MARINS, 2003, p. 14)

O Parque do Ibirapuera provocou uma ruptura na paisagem urbana paulistana, sendo alçado à condição de um "novo marco zero" de uma cidade (re) fundada sob o signo do moderno (MARINS, 2003, p. 33), resultante da atuação de novos atores sociais, imigrantes e ligados à indústria como Ciccillo Matarazzo, para quem o IV Centenário deveria ser comemorado com "cimento e concreto armado".

O texto do Anteprojeto da Exposição do IV Centenário de São Paulo salientou as funções simbólicas embutidas nas construções do parque: a Comissão do IV Centenário "encontra nesse conjunto arquitetônico a indicação perfeita e adequada, a linguagem ideal para transmitir [...] a importância e o grau de desenvolvimento técnico e industrial do grande Estado" ${ }^{\prime 19}$.

ANTEPROJETO da exposição do IV Centenário de São Paulo. Arquivo Municipal Washington Luiz, São Paulo, s/d.
A vontade de Ciccillo de comemorar os quatrocentos anos da cidade com "concreto armado" e da Comissão do IV Centenário de simbolizar o "desenvolvimento técnico do Estado" por meio da arquitetura moderna do Parque Ibirapuera atribuíram-Ihe um papel de lugar de memória do evento, ao mesmo tempo em que explicitaram certa predileção da Comissão por expressar-se por meio de alegorias urbanas. 
A ausência de elementos rementes ao catolicismo no novo espaço público da cidade ou de representações ao passado colonial afeitas aos setores conservadores da cidade não deixou de ser por eles criticada. O deputado Manoel Victor, que subscreveu supracitada Lei 2658/54 - marco inicial da reconstrução do Pátio Colégio -, proferiu um discurso na Assembleia Legislativa em que argumentou: "até o momento, tem sido apenas totalmente pagãs as festividades que se projetam [...] mas ao governo incumbe também dar uma demonstração clara, positiva e sincera de sua índole cristã" (SÃO PAULO, 1953, p. 34).

A reconstrução do Pátio do Colégio, iniciada por ocasião do IV Centenário, coadunava-se perfeitamente com anseios do deputado. Desse modo os edifícios jesuíticos começavam a ser reerguidos num contexto de grandes transformações urbanas e sociais com vistas a promover "uma reconciliação [da cidade] com o [seu] passado" (SÃO PAULO, 1953, p. 39), tal reconciliação estava assegurada, de resto, pela materialização do primeiro marco arquitetônico da história da cidade.

Se não predominaram no Ibirapuera, os setores conservadores da sociedade paulista voltaram seus interesses e suas ações para o Centro Antigo da cidade. Ainda que amplamente renovado nos anos 50 e exibindo os atributos metropolitanos de uma "sociedade de massas" como o consumo e a circulação, a mercantilização e transitoriedade de seu espaço (LIMA; CARVALHO, 1997 p. 104), o local era receptáculo de uma tradição que dificilmente o parque recentemente construído poderia exprimir.

Ao traçar um breve perfil conceitual das trajetórias dos centros urbanos, Flávio Villaça argumentou que estes se efetivaram como tais, historicamente até meados do século XIX, por exaltarem "Deus, o Estado e a classe dominante", a partir de então, porém, os dois primeiros elementos deixaram de ter grande destaque para o centro de uma "cidade capitalista", desenvolvida em favor das vicissitudes de um intenso uso do seu solo e a instalação do comércio varejista e dos serviços (VILLAÇA, 2004, p. 21).

Murillo Marx, também abordando as áreas centrais das cidades e seu caráter religioso inicial, destacou que os processos de laicização se precipitaram no Oitocentos, culminando com a vontade da cidade de inspiração burguesa e parisiense (MARX, 2003).

As transformações que o Pátio do Colégio sofreu a partir do final do século XIX até o início da sua reconstrução em 1954 corroboram as indicações dos autores. O edifício jesuítico remanescente, a Igreja de taipa de pilão, foi demolido em 1896, restando dele somente a torre que foi reformada e ganhou feição eclética [figura 3] (MELLO; MELLO, 1975, p. 35). O local passou a abrigar órgãos públicos da cidade, constituindo-se em seu centro de poder. Realçando o perfil público das obras, houve então o ajardinamento e a instalação de bancos na parte frontal ao novo edifício, transformando-a efetivamente em uma praça cívica.

O aspecto cívico, contudo, seria esvaziado nas décadas seguintes, com destaque para o período correspondente às duas gestões consecutivas do prefeito Francisco de Prestes Maia. Dessa a vez, a ressignificação do local decorreu da imperiosa necessidade de circulação viária, substrato dos planos urbanos em voga e da abertura do viaduto Boa Vista. O largo, completamente desfigurado, perdeu os equipamentos que the qualificavam como espaço para o convívio e as atividades cívicas. 
Figura 3: Demolição do antigo Palácio do Governo e torreão resultante da reforma da antiga torre da igreja. Fonte: Estado de São Paulo (1953).
Em 1930, as atividades administrativas do poder executivo municipal que ocuparam o Pátio do Colégio mudam para o bairro dos Campos Elíseos, completando um gradual processo de lacunas dos significados que o distinguiam desde a fundação da cidade. Após o banimento da religiosidade, era agora deslocada a sua função de poder. Com essas modificações, no lugar do Palácio do Governo passou a figurar a Secretaria de Educação [figura 1], que permanece no local até 1953, quando o edifício foi demolido [figura 3] para ter início a reconstrução do antigo Colégio jesuítico.

Em meio a esse processo de remodelações, os atributos religiosos e as alegorias coloniais remetentes à fundação da cidade ficaram simbolizadas ora pelo vazio do leito carroçável que se estabeleceu entre os edifícios oficiais [figura 2] ora pelo monumento Glória Imortal aos Fundadores de São Paulo do escultor italiano Amadeo Zani, inaugurado em 1925, como um dispositivo de memória coletiva que representou "o esvaziamento de todas aquelas práticas que dotavam este espaço de sua carga simbólica e ativa em significações e usos" (LIMA, 2003, P. 71).

Os artífices da reconstrução do Pátio do Colégio procuravam recuperar essas primeiras função e feição apagadas ou esvaziadas do local, numa tentativa de reverter o processo de laicização do espaço e sinalizar que seus símbolos e valores de classe remetiam aos tempos iniciais e formadores da cidade, enfim à sua fundação.

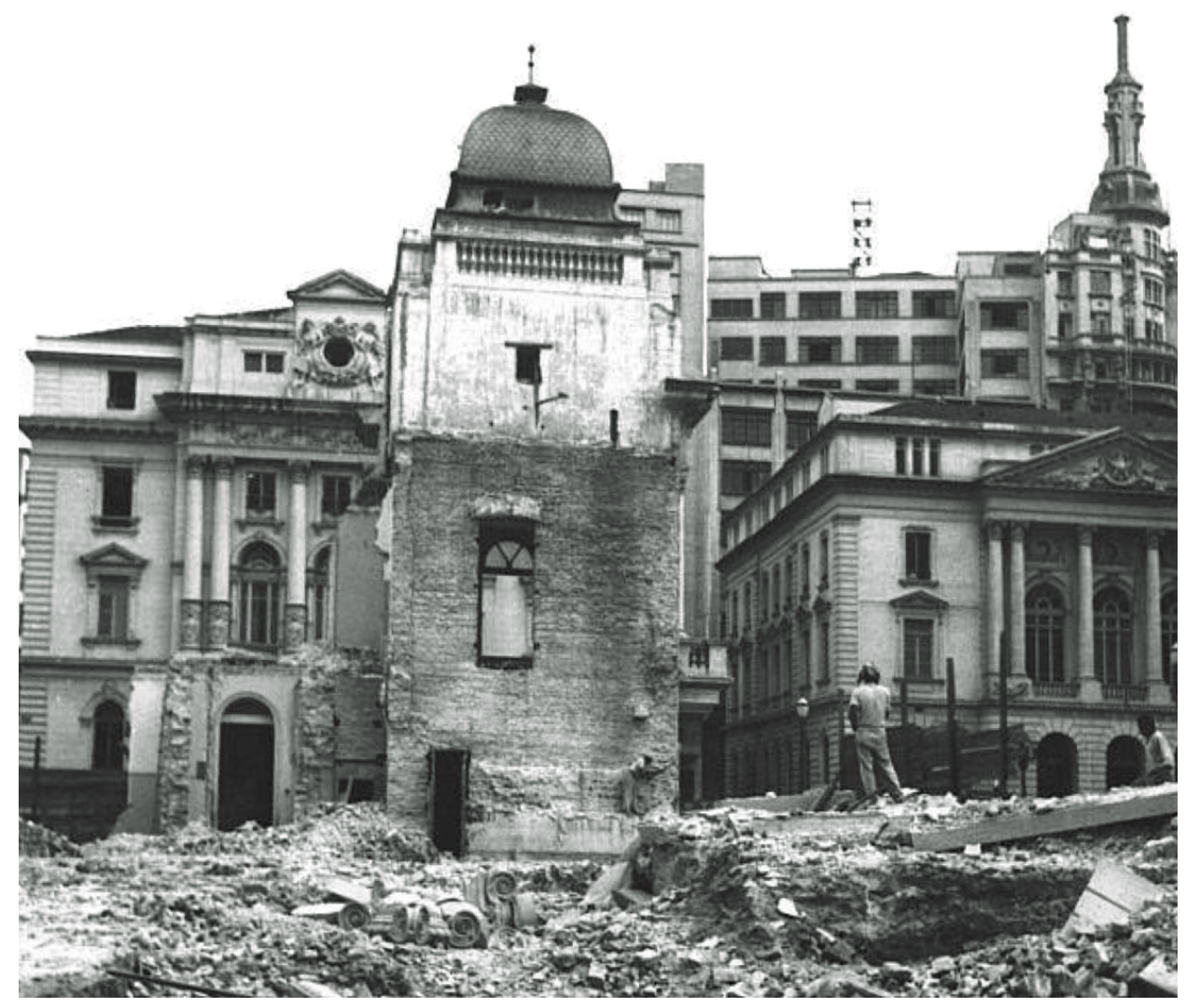




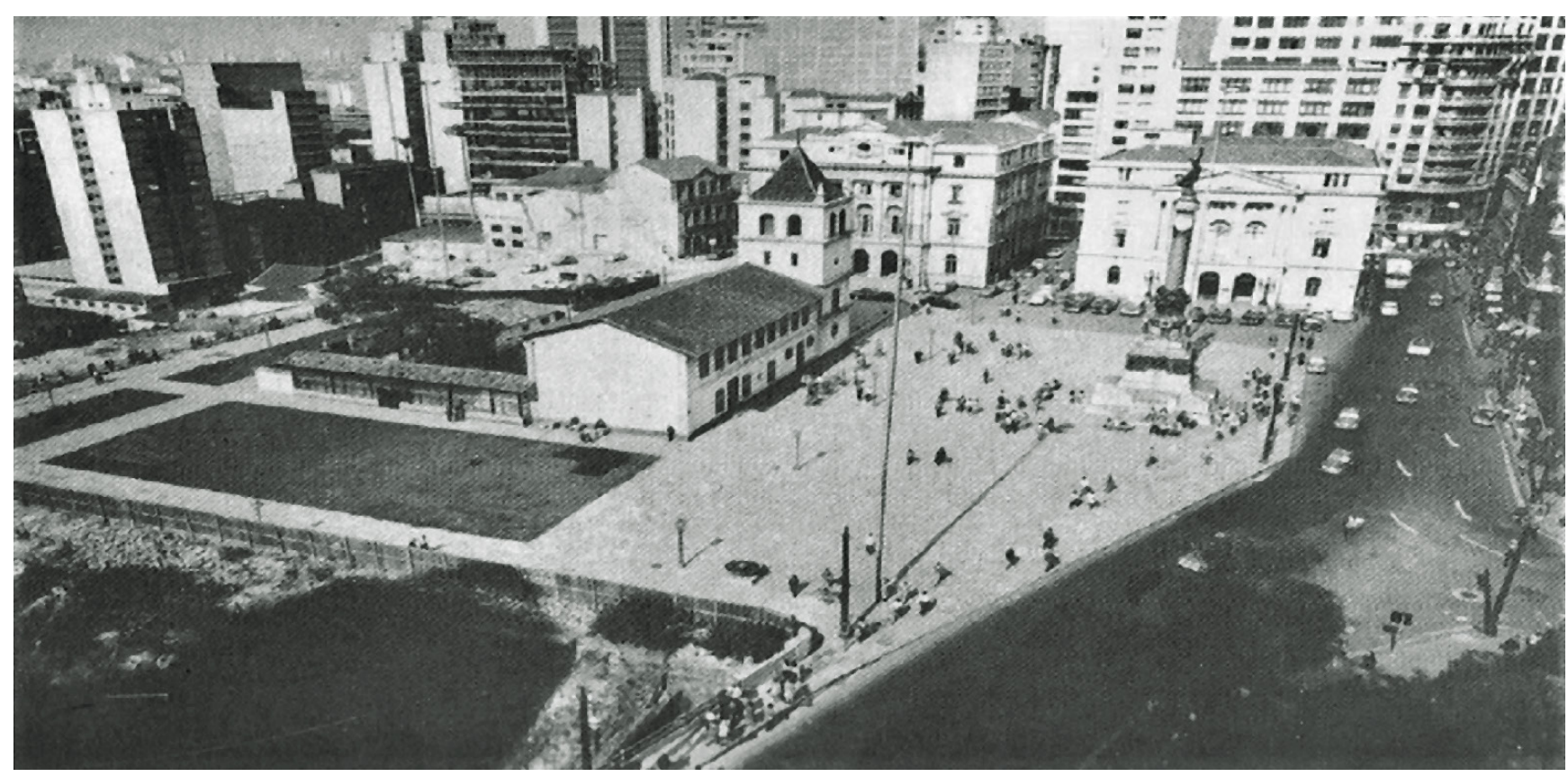

Figura 4: Vista aérea do Pátio, com o Colégio e a Torre da Igreja reconstruídos, 1971. Fonte: MORAES (1979, p. 134).
Conforme argumentou o secretário da Comissão condutora da reconstrução, José Nunes Vilhena, o Pátio do Colégio, uma vez reconstruído, representava

um Monumento Histórico, mas, um monumento-colégio, que funcionará recordando as nossas origens com as suas sagradas tradições, qual marco fundamental de nossa civilização. Ao apontá-lo dirão todos: Aqui nasceu São Paulo e este edifício é o seu marco inicial. (CARDIM FILHO, 1970, pp. 53-61)

No momento culminante da cidade celebrar seus quatrocentos anos, diferentes segmentos sociais esforçavam-se por entrelaçarem-se à sua história e firmarem-se como responsáveis pelo seu presente desenvolvimento. Em suas diferentes propostas - veiculadas no Pátio do Colégio e no Parque Ibirapuera - a Comissão presidida por Ciccillo Matarazzo e os defensores da reconstrução jesuítica, agrupados em torno da Comissão Pró Monumento Histórico do Pátio do Colégio, rivalizavam.

Reconstruir os antigos edifícios jesuíticos do Pátio do Colégio, numa cidade que negociava sua memória em seu próprio espaço urbano e estava sendo "refundada" sob o signo do moderno, era uma forma de assinalar a esses novos atores sociais, condutores das transformações, a existência de grupos cujos antigas raízes e o longínquo pertencimento à terra os tornavam "mais paulistas" e, consequentemente, mais aptos para definir os rumos da cidade.

Para esses "antigos paulistas", o local de fundação da cidade era a mais perfeita representação dos seus, então ameaçados, valores, pois retomava o passado colonial da cidade, cujos protagonistas eram considerados seus antecedentes e a tradição da católica da cidade. Valores ameaçados, mas que ainda encontravam significativa 
acolhida, uma vez que o Pátio foi "devolvido" aos jesuítas e de local inteiramente laico [figuras 1 e 2] associado ao poder público transmutou-se em local religioso [figura 4], após intensa mobilização de setores da sociedade paulistana e o apoio do meio político da cidade.

A doação do terreno do Pátio do Colégio aos jesuítas no contexto do IV Centenário de São Paulo significava a possibilidade de recuperar uma memória que pouco valor tinha para aqueles que estavam fora do circuito tradicional da cidade e comandavam a sua renovação. Para os proponentes da reconstrução, retomar a feição colonial do Pátio do Colégio era, entretanto, uma maneira de reconstruir também a sua importância social e cultural, outrora preponderante, para a cidade e também para a sua área central, que passava pela primeira vez a sofrer uma concorrência simbólica que ameaçava sua primazia, constituída pelo "rival" Parque Ibirapuera. A reconstrução foi investida de uma função social e memorial que visava, assim, explicitar o antigo marco como símbolo de velhos paulistas, perante a profusão de tantos outros novos e festejados símbolos postulantes de mudanças.

\section{Referências bibliográficas}

A ASSOCIAÇÃO dos cavaleiros de São Paulo e as comemorações do próximo dia 25. Folha da Manhã, São Paulo, p. 10, 22 jan. 1957

A RECONSTRUÇÃO dos primitivos edifícios. O Correio Paulistano, São Paulo, pp. 1-2, 17 dez. 1953.

ALTINO Arantes. O Estado de São Paulo, São Paulo, p. 14, 06 jul. 1965.

O Estado de São Paulo, São Paulo, p. 14, 06 jul. 1965.

ANTEPROJETO da exposição do IV Centenário de São Paulo. Arquivo Municipal Washington Luiz, São Paulo, s/d.

AOS ELEITORES associados à confederação das famílias cristãs. O Estado de São Paulo, São Paulo, p. 4, 3 out. 1954.

ARRUDA, Maria Arminda do Nascimento. Metrópole e Cultura: São Paulo no meio do século XX. Bauru, SP: Edusc, 2001.

CAMPANHA da saca de café para a basílica de N. S. Aparecida. Folha da Manhã, São Paulo, p. 5, 1 mai. 1958.

CAMPANHA de gratidão aos fundadores de São Paulo. Folha da Manhã, São Paulo, p. 1, 24 set. 1955.

CAMPANHA pela canonização do padre José de Anchieta. O Correio Paulistano, São Paulo, p. 513 jul. 1962 .

CANADO JUNIOR, Roberto dos Santos. Embates pela memória: a reconstrução do conjunto jesuítico do Pátio do Colégio (1941-1979). 2014. Dissertação (Mestrado em História e Fundamentos da Arquitetura e do Urbanismo) - Faculdade de Arquitetura e Urbanismo, Universidade de São Paulo, São Paulo, 2014.

CARDIM FILHO, Carlos A. Gomes. Projeto do Pátio do Colégio. Revista do Ateneu Paulista de História. n. 7, pp. 53 - 61, São Paulo, 1970.

CASTRO, Fernando Pedreira de. O Pátio do Colégio. Resumo Histórico e Projeto de Reconstrução (Opúsculo de simples divulgação), 1954. 
CENTENÁRIO de Maria Antonieta Cesar Salgado. Folha de São Paulo, São Paulo, p. 2, 9 mai. 1963.

CONSIDERA-SE oportuna e necessária a reconstrução da Igreja edificada por Anchieta no Pátio do Colégio. Folha da manhã, São Paulo, p. 7, 6 out.1953.

D. MARIA Antonieta Cesar Salgado. O Estado de São Paulo, São Paulo, p. 5, 16 ago. 1957.

EXCURSÃO a cidades tradicionais do estado. Folha da manhã, São Paulo, p. 6, 12 mar. 1955. Folha de São Paulo, São Paulo, p. 30. 10 fev. 1976.

HOJE a posse do Sr. Cesar Salgado no cargo de Procurador-Geral da Justiça. Folha da Manhã, São Paulo, 3 fev. 1951.

INAUGUROU-SE ontem na praça da Sé o monumento ao padre José de Anchieta. Folha da Manhã, São Paulo, p. 7, 9 dez. 1954.

JOSÉ Augusto Cesar Salgado. O Estado de São Paulo, São Paulo, p. 21, 10 abril 1979.

LEITE, Manfredo. Altino Arantes e a Religião. O Correio Paulistano, São Paulo, p. 6, 2 out. 1956.

LIMA, Solange Ferraz de. Pátio do Colégio, Largo do Palácio. Anais do Museu Paulista, ano/ vol. 6/7, n. 007. São Paulo, 2003.

LIMA, Solange Ferraz de.; CARVALHO, Vânia Carneiro de. Fotografia e Cidade: da razão urbana à lógica do consumo: álbuns da cidade de São Paulo, 1887 - 1954. Campinas: Mercado das Letras; FAPESP, 1997.

LOFEGO, Silvio Luiz. IV Centenário da cidade de São Paulo: uma cidade entre o passado e o futuro. São Paulo: Annablume, 2004.

MARINS, Paulo César Garcez. O Parque do Ibirapuera e a construção da identidade paulista. Anais do Museu Paulista: História e Cultura Material, São Paulo, v. 6/7, pp. 9-36, 2003.

MARX, Murillo. Nosso chão: do sagrado ao profano. São Paulo: Edusp, 2003.

MAYUMI, Lia. Taipa, canela-preta e concreto: Estudo sobre o restauro de casas bandeirista. São Paulo: Romano Guerra Editora, 2008.

MELLO, Alexandre; MELLO, Nilva R. Vida e Morte da Igreja do Colégio. Revista do Arquivo Municipal de São Paulo. São Paulo, 1975.

MISSA campal em São Vicente para comemorar a chegada àquela enseada dos primeiros jesuítas. Folha da noite, São Paulo, p. 1, 26 jan. 1954.

MONUMENTO á Anchieta. Folha da Manhã, São Paulo, p. 3, 29 jun. 1954.

MORAES, Geraldo Dutra de. A igreja e o colégio dos jesuítas de São Paulo.São Paulo: Gráfica Municipal, 1979.

MOVIMENTO feminino pró-igreja do Pátio do Colégio. O Correio Paulistano, São Paulo, p. 7, 20 mai. 1953.

OLIVEIRA, Fabiano Lemes de; ANDRADE, Carlos Roberto Monteiro de. Projetos para o parque do Ibirapuera: de Manequinho Lopes a Niemeyer (1926-1954). 2003.Universidade de São Paulo, São Carlos, 2003.

PRÓ-CONSTRUÇÃO da basílica da padroeira do Brasil. Folha da Manhã, São Paulo, p. 3, 13 jul. 1958.

SAKURAI, Célia Os Primeiros Políticos de Origem Japonesa no Brasil. Revista do Acervo Histórico da Assembléia Legislativa do Estado de São Paulo, São Paulo. n. 4, pp. 87-97, 2005.

SALGADO, José Augusto Cesar. O Pátio do Colégio: História de uma Igreja e uma Escola. São Paulo, Gráfica Municipal de São Paulo, 1976. 
SÃO PAULO (Estado). Lei n 2.658 de 21 de janeiro de 1954. Diário Oficial do Estado de São Paulo, São Paulo, n 17 , ano 64, p. 1, 1954.

Projeto de Lei n. 1298/53 de 21 de outubro de 1953. Assembleia Legislativa do Estado de São Paulo, São Paulo, 1953.

Sessão da Assembleia Legislativa. Diário Oficial do Estado de São Paulo, São Paulo، n 272, ano 63 pp. 39-40, 1953.

Sessão da Assembleia Legislativa. Diário Oficial do Estado de São Paulo, São Paulo, num. 282, ano 63, pp. 38-39, 1953.

Sessão da Assembleia Legislativa. Diário Oficial do Estado de São Paulo, São Paulo, num. 275, ano 63, p. 34, 1953.

Sessão da Assembleia Legislativa. Diário Oficial do Estado de São Paulo, São Paulo, num. 272, ano 63, p. 39, 1953.

Sessão da Assembleia. Diário Oficial do Estado de São Paulo, São Paulo, n. 275, p. 28, 1953.

Sessão da Assembleia. Diário Oficial do Estado de São Paulo, São Paulo, num. 272, ano 63, p. 39, 1953

SALIBA, Elias Thomé. Histórias, memórias, tramas e dramas da identidade paulistana. In: PORTA, Paula (org.). História da Cidade de São Paulo: a cidade da primeira metade do século XX (1890-1930). São Paulo, Paz e Terra, 2004.

SERÁ entregue um pergaminho ao papa em nome da união dos amigos da padroeira de Brasil. Folha da Manhã, São Paulo, 20 mai. 1956.

TRIGO, Maria Helena Bueno. Os Paulistas de Quatrocentos Anos: Ser e Parecer. São Paulo, Annablume, 2001.

VILLAÇA, Flávio. Reflexões sobre o centro de São Paulo. In: SCHICCHI, Maria Cristina; BENFATTI, Dênio. (orgs). Urbanismo: dossiê São Paulo - Rio de Janeiro. Campinas: PUCCAMP. PROURB;Óculum Ensaios, 2004.

VILHENA, José Nunes de. Centenário da Chegada de Anchieta no Brasil. O Correio Paulistano, São Paulo, p. 6, 13 jul. 1956. 